Article

\title{
Identification of bioactive compounds and antioxidant activity in leaves and fruits of Actinidia arguta accessions from northeastern China
}

\author{
Changhua Tan ${ }^{1}$, Zhigang Wang ${ }^{2}$, Xiuli Feng ${ }^{3}$, Muhammad Irfan ${ }^{4}$ and Changjiang Liu 1,* \\ ${ }^{1}$ Department of Food Science, Shenyang Agricultural University, Shenyang, 110866, Liaoning, China; \\ tch0861@163.com (C.T.) \\ ${ }^{2}$ Institute of Vegetable, Liaoning Academy of Agricultural Science; Shenyang, 110161, Liaoning, China; \\ wang9505@qq.com (Z.W.) \\ ${ }^{3}$ Institute of Flower, Liaoning Academy of Agricultural Science; Shenyang, 110161, Liaoning, China; \\ fengxiuli_1974@163.com (X.F.) \\ ${ }^{4}$ Department of Biotechnology, University of Sargodha, Sargodha Pakistan, irfan.biotechnologist@gmail.com \\ (M.I) \\ * Correspondence: liuarguta@163.com (C. Liu);
}

\begin{abstract}
Actinidia arguta (Sieb. et Zucc.) Planch. ex Miq. is abundant of vitamin C and bioactive compounds with high antioxidant activities. In this study, eight wild A. arguta accessions from different areas in Northeast China were collected. Some bioactive compounds were examined on the different tissues of different germplasms including four kinds of leaves, petioles and fruits. The method of UPLC-MS was used to detect the flavonoid compounds. The results showed that some bioactive compounds including vitamin $\mathrm{C}$, soluble sugar, free amino acid, total phenolics and flavonoids content showed significant differences between six tissues of $A$. arguta accessions and showed significant variability with maturity. In eight accessions, the highest vitamin $C$ content was found in young apical leaves of 'CBS-6' (7.47 mg/g fresh weight), and the highest soluble sugar content was in fruits of 'CJ-1' (196.52 mg/g fresh weight) and the highest total phenolic content and total flavonoids content were in young apical leaves of 'CBS-11' (3.48 mg/g fresh weight) and of 'CBS-3' (2.00 mg/g fresh weight), respectively. Ten flavonoid compounds including kaempferol, isorhamnetin and quercetin were detected in leaves, petioles and fruits. The total content of flavonoids were highest in young apical leaves $(10219.84 \mu \mathrm{g} \cdot \mathrm{g}-1)$ and the lowest in fruits $(78.75$ $\mu \mathrm{g} \cdot \mathrm{g}-1)$. Based on the comparison of the contents of several bioactive compounds, the two accessions ' $\mathrm{CJ}-1$ ' and 'CBS- 8 ' had relatively outstanding performance, and in the comprehensive evaluation of the antioxidant activity among different tissues, the young leaves had the strongest antioxidant activity. These results highlighted the antioxidant potentialities of $A$. arguta leaves as a major source of phenolics and vitamin $C$ as well as flavonoids. It provided a theoretical basis for the utilization of leaves of A. arguta.
\end{abstract}

Keywords: Actinidia arguta; leaf; bioactivity; antioxidant activity; LC-MS/MS

\section{Introduction}

Actinidia arguta (Sieb. et Zucc.) Planch. ex Miq. is well known as hardy kiwifruit with good cold resistance, which is native to East Asia and different from other commercial kiwifruit [1]. A. arguta is widely distributed from $22^{\circ} \mathrm{N}$ to $47^{\circ} \mathrm{N}$ in latitude throughout of China [2]. It has a smooth and edible skin, good taste and flavour [3]. A. arguta is known to be very high vitamin C content and rich bioactive and volatile compounds with high antioxidant activities [4], such as flavonoids, phenolic compounds, etc $[5,6]$. At present, its growing commercially has become very popular in several countries including New Zealand, some European countries (Canada, Japan, the United States) and China [7-9]. 
Kiwifruit has been recorded in China for more than 2,000 years. It has rich nutritional value, strong protective activity and good medicinal value [10-12]. In recent years, many of the previous studies have focused on the fruits of $A$. arguta [13-15] and kiwifruit [16], their fruits have a high antioxidant capacity [17,18] and are also an important source of bioactive substances [19], such as high levels of vitamins, phenolics and flavonoids, etc. Some researchers have been studying flavonoid metabolites and other polyphenol content and evaluated the nutritional values of $A$. arguta fruits [20,21]. Yu et al. investigated the flavonoid compounds in A. chinensis and A. arguta fruits and identified a total of 125 flavonoids and 39 metabolites in two kiwi berries, which indicated that flavonoid components were abundant in kiwifruit and kiwi berry [22]. Although the bioactivity and antioxidant activity of the $A$. arguta fruit has been well characterized [4,23], there have been few studies investigating the bioactivity of $A$. arguta leaves.

A. arguta leaves are accumulated during the pruning each year, which are an affordable and abundant raw material as a kind of byproducts of farming. As early as 1977, A. arguta was recorded that it could be used as a medicinal food homologous plant. Its roots and leaves had the effects of clearing heat and promoting diuresis and strengthening stomach [24]. Cyboran et al. evidenced the effect of $A$. arguta leaf extract which could be used as an effective natural antioxidant protecting the body against external oxidizing agents and also be food additives or dietary supplements against food aging from oxidation-induced. So they are expected applicated in the cosmetic, medicine, and food industries because of rich bioactive compounds. [25]. Webby identified a new flavonol triglycoside and isolated the kaempferol analogues in leaves of A. arguta [26]. Almeida et al. evaluated the leaves of $A$. arguta regarding antioxidant and antimicrobial activity, as well as radical scavenging activity for the first time, identified and quantified phenolic compounds [19]. In this study, eight wild A. arguta accessions from different areas were collected. They were growing strong, six of them were female plants, the fruits were all green, and the quality was good, and there were two male accessions, with a large amount of blooms and concentrated flowering period. Using LC-MS/MS and a series of physiological and biochemical substances to determine the leaves at different developmental stages of eight accessions, it was expected that new germplasm could be screened out, which would lay the foundation for the utilization of leaves of $A$ arguta.

\section{Results}

\subsection{Determination of bioactive compounds in leaves and fruits of A. arguta}

\subsubsection{Vitamin $\mathrm{C}(\mathrm{Vc})$ content}

Overall, the Vc content in the eight A. arguta accessions leaves at different stages of maturity performed significant differences. The Vc content in young tissues (eg. YAL, P and QL) was slightly higher than that of old tissues (eg. HL and ML), and declined with leaf maturity. A continuous decrease was observed in Vc content of eight accessions leaves as leaf maturity (from YAL to ML), such as 'CJ-1' where it ranged from 7.25 to $3.44 \mathrm{mg} / \mathrm{g}$ fresh weight from young apical leaves to mature leaves, as well as 'HY-1', 'BYS-13', 'CBS-8', etc. Interestingly, the Vc content in the petioles of young leaves was similar to that in young leaves, and three accessions were even higher than those in young leaves, such as 'BYS-13', 'BYS-5' and 'CBS-11'. On the other hand, Vc content in fruits was lower than those of immature leaves and petioles and higher than mature leaves. By comparing the Vc content of leaves, petioles and fruits of the eight accessions in Figure 1, it was found that the Vc contents in YAL leaves and fruits of 'CBS- 6 ' were the highest among the eight accessions, being 7.47 $\mathrm{mg} / \mathrm{g}$ and $4.47 \mathrm{mg} / \mathrm{g}$ fresh weight, respectively, followed by 'CBS-3' and 'CJ-1', while 'BYS-13' was the lowest.

\subsubsection{Soluble sugar content (SSC)}


The results of the SSC in six tissues of the eight accessions confirmed that the highest content was in the fruits, followed by the leaves, and the petioles had the lowest content (Fig. 2). While, the SSC in the leaves of each accession mostly increased with the gradual maturity of the

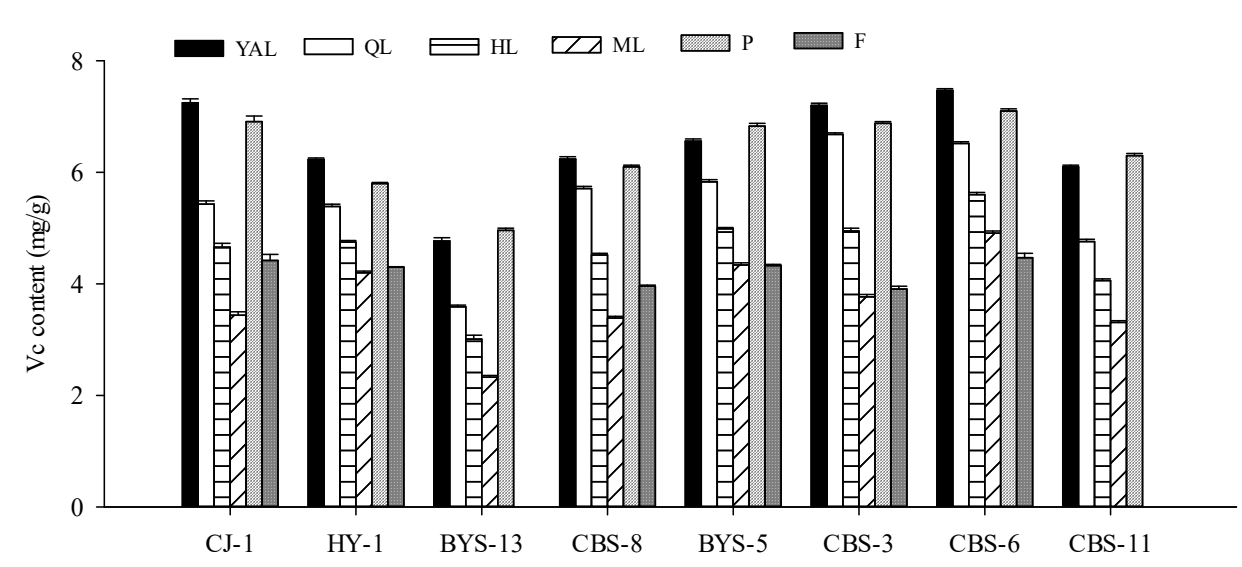

Figure 1. Comparison of $\mathrm{Vc}$ content of different tissues in eight A. arguta accessions.

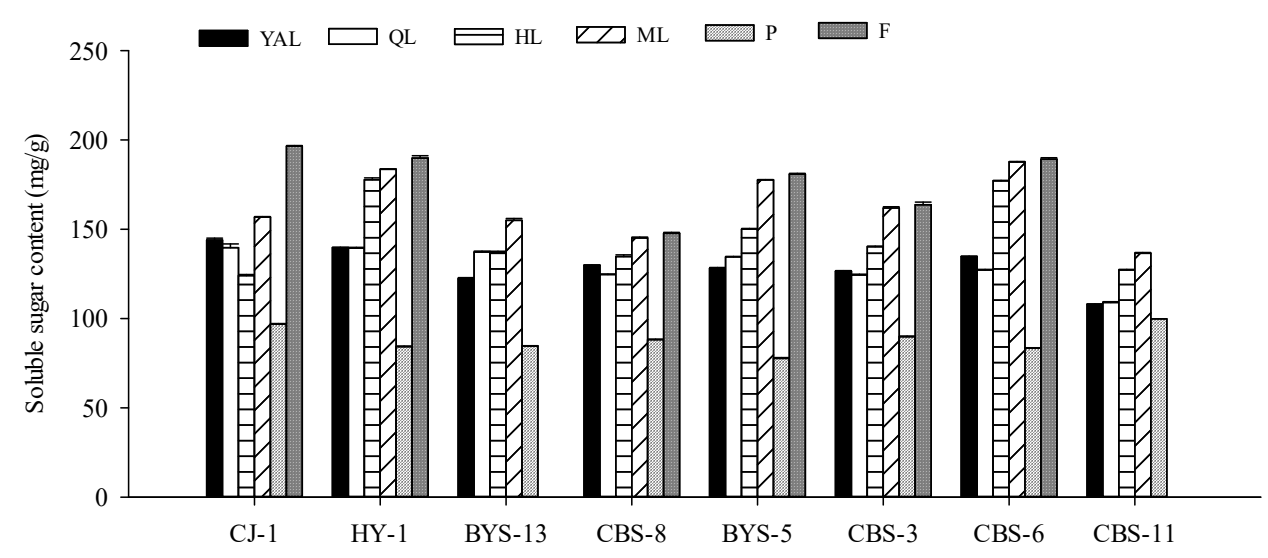

Figure 2. Comparison of soluble sugar content of different tissues in eight A. arguta accessions.

leaves and the highest content of leaves was in mature leaves (ML). In 'CJ-1', the SSC in mature leaves (ML, $156.85 \mathrm{mg} / \mathrm{g}$ ) was lower than that in fruits, higher than that in other tissues, and 61.88\% higher than that in petioles. The highest SSC (196.52 mg/g fresh weight) was obtained from the mature fruits of ' $\mathrm{CJ}-1$ '. The other five female accessions were similar to 'CJ-1', the highest SSC was in fruits and the lowest content in petioles. In male accessions, the highest SSC was in mature leaves. On the other hand, by comparing the SSC of the eight accessions in Figure 2, the content of 'CJ-1', 'HY-1', and 'CBS-6' in different tissues was relatively higher than the other five accessions, and 'CBS-11' was the lowest.

\subsubsection{Free amino acid (FAA) content}

The FAA content in young tissues (eg. YAL, P and QL) was significantly higher than that of old tissues (eg. HL and ML), and declined with leaf maturity, the lowest content was in fruits. In 'CJ-1', the content of FAA in petiole was the highest, which was $1.55 \mathrm{mg} / \mathrm{g}$ fresh weight, extremely higher than that in other tissues. The lowest content was observed in mature leaves and fruit (ML and F of 'CJ-1', $0.14 \mathrm{mg} / \mathrm{g}$ fresh weight), which was also the lowest among the eight accessions. Furthermore, it was found that the highest content was in QL of 'BYS-13' with $1.69 \mathrm{mg} / \mathrm{g}$ fresh weight, which was 
also the highest among the eight accessions. By comparing the FAA content of the eight accessions in Figure 3, it was found that the contents in P of 'CJ-1', and in YAL and QL of 'BYS-13' were higher than the other six accessions, while there was no significant difference among other six accessions.

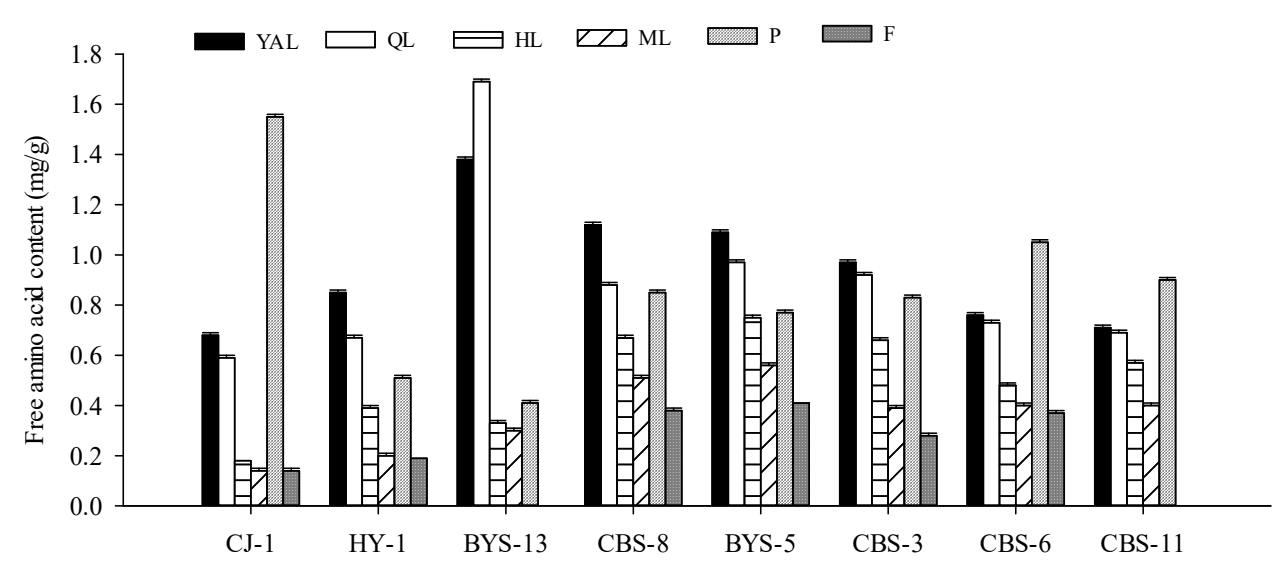

Figure 3. Comparison of free amino acid content of different tissues in eight A. arguta accessions.

\subsubsection{Total phenolic content (TPC)}

A continuous decrease was observed in TPC of the eight accessions in leaves as leaf maturity (from YAL to ML). While the highest content was in fruits of six female accessions, and the values in petioles of each accession were the lowest. In 'CJ-1', the TPC in fruits was higher than that in leaves and petioles with significant differences, that in petioles was the lowest $(0.37 \mathrm{mg} / \mathrm{g}$ fresh weight), and the highest content in fruits was $2.96 \mathrm{mg} / \mathrm{g}$ fresh weight, the difference was eight times. By comparing the TPC of the eight accessions in Figure 4, it was found that the contents of different tissues in 'BYS-5' were the highest in fruits ( $3.25 \mathrm{mg} / \mathrm{g}$ fresh weight), while 'BYS-13' were lower than the other accessions, meanwhile the highest value $(3.48 \mathrm{mg} / \mathrm{g})$ among the eight accessions was observed in the YAL of 'CBS-11'.

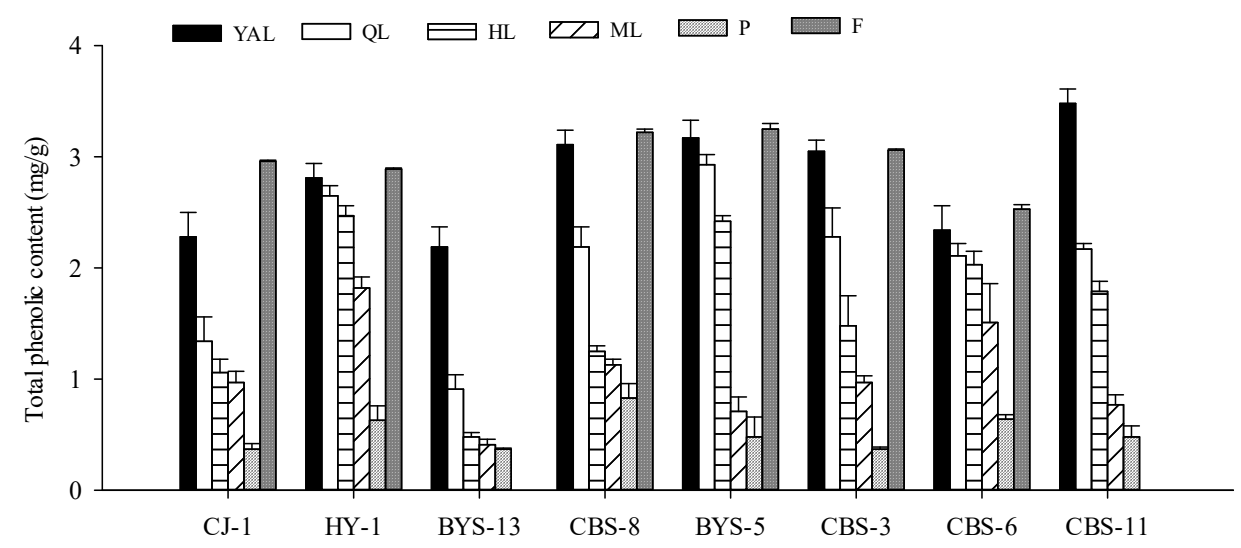

Figure 4. Comparison of total phenolic content of different tissues in eight A. arguta accessions.

\subsubsection{Total flavonoids content (TFC)}

Overall, the TFC in the eight $A$. arguta accessions leaves performed continuous decrease with the leaf maturity. The TFC of the young leaves were higher than that of the old leaves, while those in petioles were higher than fruits, but lower than leaves among the eight accessions, the lowest content was in fruits. The TFC of YAL in the eight accessions were highest, followed by QL, HL and 
ML. When compared to ML among the eight accessions, the TFC of YAL was higher from 1.83-fold to 3.41-fold. In 'CJ-1', the TFC in different tissues were in the order of leaf $>$ petiole $>$ fruit, and the content in YAL (1.83 mg/g) was 6.3 folds higher than that in fruit (F, $0.29 \mathrm{mg} / \mathrm{g})$. By comparing the TFC of the eight accessions (Figure 5), it was found that there was no significant difference among the eight accessions; 'CJ-1' 'CBS-8' and 'CBS-3' were slightly higher than the other six accessions.

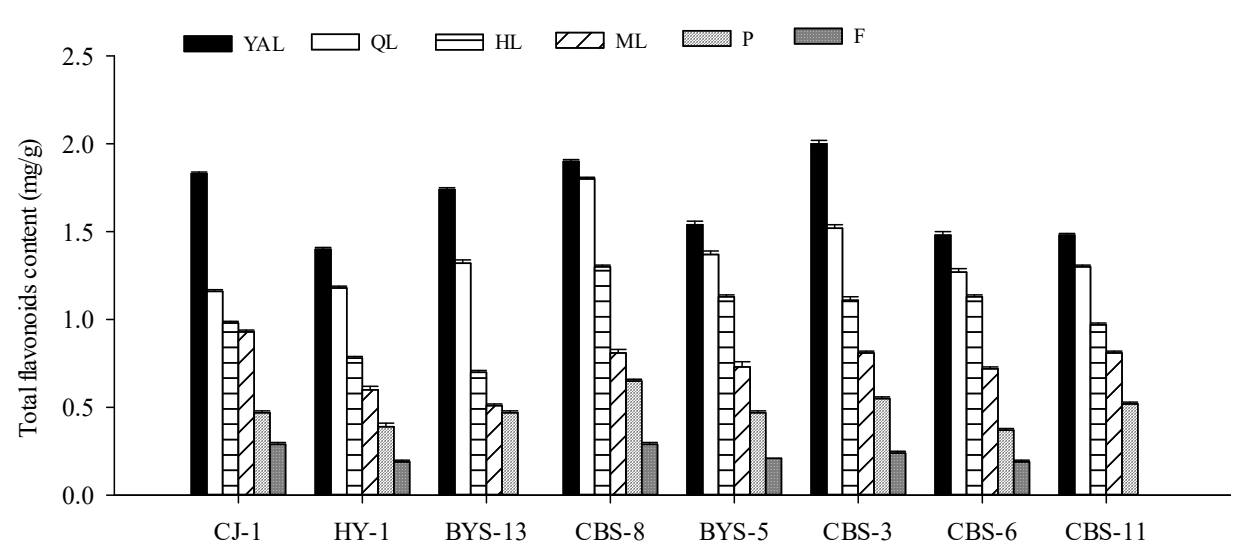

Figure 5. Comparison of total flavonoids content of different tissues in eight A. arguta accessions.

\subsection{Antioxidant activity determinations}

\subsubsection{ABTS free radical scavenging assay}

It was observed that ABTS radical scavenging activity in the eight $A$. arguta accessions leaves performed continuous decrease with the leaf maturity. The ABTS radical scavenging activity of the young leaves were higher than that of the old leaves, and higher than that of petioles and fruits, the lowest values were in fruits. Interestingly, ABTS radical scavenging activity in the petioles of young leaves was almost the lowest not similar to that in young leaves. The ABTS radical scavenging activity of YAL in the eight accessions were highest, followed by QL, HL and ML, such as 'CJ-1' where it ranged from 41.51 to $14.90 \mathrm{mmol} / \mathrm{g}$ fresh weight from young apical leaves to mature leaves, as well as 'HY-1', 'BYS-13', 'BYS-5' and 'CBS-6', were also showed similar trend. On the other hand, in ' $\mathrm{CJ}-1$ ', except for $\mathrm{ML}$, the ABTS radical scavenging activity of leaves was greater than that of petioles and fruits, and the ABTS radical scavenging activity of YAL (41.51 mmol/g) was 2.5 times the fruit $(16.65 \mathrm{mmol} / \mathrm{g})$. By comparing ABTS radical scavenging activity of the eight accessions (Figure 6), it was found that 'CJ-1' was slightly higher than the other accessions and the lowest was 'BYS-13'. The highest value in fruits was in 'CBS-3', that was $18.51 \mathrm{mmol} / \mathrm{g}$.

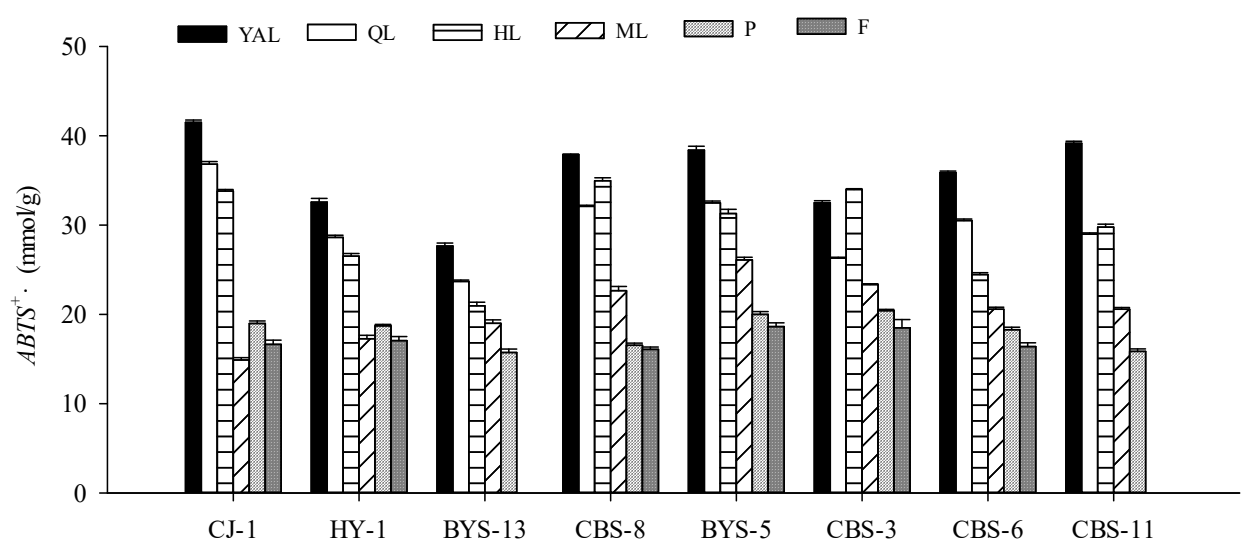

Figure 6. Comparison of ABTS+ antioxidant activity of different tissues in eight A. arguta accessions. 


\subsubsection{DPPH free radical scavenging assay}

It was observed that DPPH radical scavenging activity in the eight $A$. arguta accessions leaves showed continuous decrease with the leaf maturity as similar to that of ABTS radical scavenging activity. The DPPH radical scavenging activity of the young leaves and petioles was higher than that of the old leaves. While the values in fruits were only higher than mature leaves. The DPPH radical scavenging activity of YAL in eight accessions was highest except 'BYS-13', 'CBS-3' and 'CBS-8', followed by QL, HL and ML, such as 'CJ-1' where it ranged from 91.22 to $71.29 \mu \mathrm{mol}$ TE/L from young apical leaves to mature leaves. In 'CJ-1', the DPPH radical scavenging activity of YAL (91.22 $\mu \mathrm{mol} \mathrm{TE} / \mathrm{L})$ was 1.3 times than the fruit, and the value of fruits $(71.29 \mu \mathrm{mol} \mathrm{TE} / \mathrm{L})$ was only higher than ML (65.60 $\mu \mathrm{mol}$ TE/L). By comparing DPPH radical scavenging activity of leaves and petioles with different maturity of the eight accessions (Figure 7), it was found that 'CJ-1' was slightly higher than the other accessions, while there was no significant difference among these accessions.

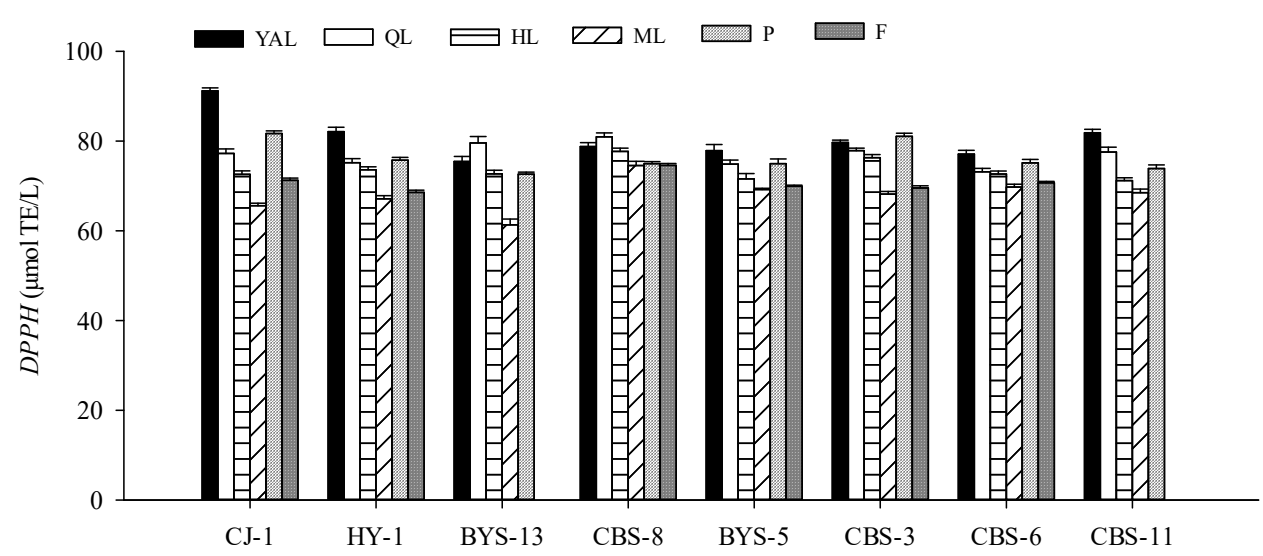

Figure 7. Comparison of DPPH antioxidant activity of different tissues in the A. arguta accessions.

\subsubsection{Correlation between bioactive compounds and antioxidant activity}

To identify the relationship between the main bioactive substances in the leaves of $A$. arguta and their relationship with the ability to scavenge free radicals, a correlation analysis was done and the results were presented in Table 1 . The Vc content and the soluble sugar content had significantly

Table 1. Correlation analysis between main bioactive substances and free radical scavenging ability of Actinidia arguta

\begin{tabular}{|c|c|c|c|c|c|c|}
\hline Parameter & $\begin{array}{l}\text { Vc } \\
\text { content }\end{array}$ & $\begin{array}{l}\text { Soluble } \\
\text { sugar } \\
\text { content }\end{array}$ & $\begin{array}{l}\text { FAA } \\
\text { content }\end{array}$ & $\begin{array}{l}\text { Total } \\
\text { phenolic } \\
\text { content }\end{array}$ & $\begin{array}{l}\text { Total } \\
\text { flavonoids } \\
\text { content }\end{array}$ & ABTS+. \\
\hline Soluble sugar & -0.936 & & & & & \\
\hline FAA & $0.957^{*}$ & $-0.969^{*}$ & & & & \\
\hline Total phenolic & $0.997^{* *}$ & -0.917 & 0.933 & & & \\
\hline Total flavonoids & $0.999^{* *}$ & -0.943 & $0.968^{*}$ & $0.993^{* *}$ & & \\
\hline ABTS+. & 0.943 & -0.905 & 0.849 & $0.956^{*}$ & 0.932 & \\
\hline DPPH. & $0.989^{*}$ & $-0.967^{*}$ & $0.952^{*}$ & $0.986^{*}$ & $0.987^{*}$ & $0.970^{*}$ \\
\hline
\end{tabular}

Note: Data are statistically analysed using Pearson's correlation coefficient test. The correlation coefficient $\mathrm{r}$ value in the table; ${ }^{*}$ indicates significant correlation at $\mathrm{a}=0.05$ level (both sides); ** indicates significant correlation at $\mathrm{a}=0.01$ level (both sides); $\mathrm{r}>0$ is positive correlation, $\mathrm{r}<0$ is negative correlation 
negative correlation $(\mathrm{r} 2=-0.936 ; \mathrm{p}<0.05)$, and was extremely positive correlation with FAA content $(\mathrm{r} 2=0.957 ; \mathrm{p}<0.05)$, TPC $(\mathrm{r} 2=0.997 ; \mathrm{p}<0.01)$ and TFC $(\mathrm{r} 2=0.999 ; \mathrm{p}<0.05)$. The soluble sugar content and FAA content $(\mathrm{r} 2=-0.969 ; \mathrm{p}<0.05)$ exhibited significantly negative correlation. An extremely positive correlation was found between the FAA content and TFC $(\mathrm{r} 2=0.968 ; \mathrm{p}<0.05)$. The strong positive correlations was observed between TPC and TFC, which accounted for, $\mathrm{r} 2=0.993$ at $\mathrm{p}<0.01$.

The results showed that Vc content, FAA content as well as TPC and TFC were significantly positively correlated with DPPH free radical scavenging rate $(\mathrm{r} 2=0.989,0.952,0.986,0.987$, respectively; $\mathrm{p}<0.05)$, while significant negative correlation was found between soluble sugar content and DPPH free radical scavenging rate $(\mathrm{r} 2=-0.967 ; \mathrm{p}<0.05)$. A strong positive correlation was found between TPC and ABTS free radical scavenging rate $(\mathrm{r} 2=0.956 ; \mathrm{p}<0.05)$. Regarding the ABTS and DPPH radical scavenging activities, the correlation determined was positive $(\mathrm{r} 2=0.970 ; \mathrm{p}<0.05)$.

\subsection{Analysis of Flavonoids Compounds Using LC-MS/MS}

By LC-UV-MS analysis, the composition of flavonoids in A arguta could be identified by the UV-vis spectrum, elution order, retention time and MS fragmentation pattern by reference with published data [27]. A total of ten peaks were detected in the flavonoid extract of A. arguta, which were identified by the retention time in LC-MS/MS system, elution order, $\lambda$ max in the visible region, main $\mathrm{MS}^{2}$ fragments and molecular ion (Figure S1). Some components had similar absorption UV spectra. The maximum absorption peaks were at $240-280 \mathrm{~nm}$ and $330-380 \mathrm{~nm}$. Therefore, it was inferred that these components belonged to the flavonol glycoside compound (Figure S1). As shown in Figure S1, for example, a series of strong $[\mathrm{M}+\mathrm{H}]+$ ions were observed in the $(+)$ ESI-MS spectrum of the flavonoid extract of $A$. arguta leaves, including $\mathrm{m} / \mathrm{z} 579, \mathrm{~m} / \mathrm{z} 595, \mathrm{~m} / \mathrm{z} 625, \mathrm{~m} / \mathrm{z} 653, \mathrm{~m} / \mathrm{z} 757$, etc., as well as stronger $\mathrm{Y} 0+$ ions, [Y0+H]- ions and other fragment ions, such as $\mathrm{m} / \mathrm{z} 285, \mathrm{~m} / \mathrm{z} 300, \mathrm{~m} / \mathrm{z} 301$, $\mathrm{m} / \mathrm{z} 314, \mathrm{~m} / \mathrm{z} 315, \mathrm{~m} / \mathrm{z} 316$ plasma and m/z 271, m/z 255, m/z 243, m/z 227 and other fragment ions (Table 2). It was preliminarily determined to be aglycone components belonging to isorhamnetin, quercetin and kaempferol. From the above information, it could be inferred that the compound was replaced by one glycoside and two glycosides. On the basis of the UV-vis spectrum, retention time, main MS2 fragments and molecular ion, F1, F2 and F3 were tentatively established as Kaempferol-3-O-Rutinoside (cis), Kaempferol-3-O-Rutinoside (trans) and kaempferol-3-Oneohesperidoside (P), respectively. The possible structure of F4 or F5 was isorhamnetin-3-O- $\alpha$-L-rhamnosyl-( $1 \rightarrow 3)-\alpha$-L-rhamnosyl-( $(1 \rightarrow 6)-\beta$-D- Galactoside. F6 was identified as isorhamnetin-3-O-neohesperidoside (P) (cis) for the moment, F7 might be isorhamnetin-3-O-neohesperidoside (P) (trans) and F8 might be isorhamnetin-3-O-rutinoside. The possible structure of F9 was isorhamnetin-3-O-neohespeidoside or isorhamnetin-7-O-(4"-O-acetyl-glucosyl)-3 -O-xyloside. F10 was tentatively determined as Quercetin-3-O-rhamnoglycoside (Figure S2).

The content of ten flavonoid compounds in different tissues of ' $\mathrm{CJ}-1$ ' was quantitatively analyzed (Table 4). Quercetin -3-O- rhamnoglycoside was among the highest content of total flavonoids in the five tissues, accounting for $32.62 \%$ in YAL, 29.71\% in QL, 31.58\% in ML, $58.95 \%$ in $\mathrm{P}$, and $56.55 \%$ in $\mathrm{F}$, respectively. Kaempferol, isorhamnetin, and quercetin compounds were found in leaves (YAL, QL, HL and ML), petioles (P) and fruits (F). The highest level of flavonoid accumulation was detected in leaves, and flavonoids in $\mathrm{P}$ and $\mathrm{F}$ were $151.63 \mu \mathrm{g} \cdot \mathrm{g}^{-1}$ and $78.75 \mu \mathrm{g} \cdot \mathrm{g}^{-1}$, respectively. It varied significantly in different types of leaves, which was $10219.84 \mu \mathrm{g} \cdot \mathrm{g}^{-1}, 4977.83 \mu \mathrm{g} \cdot \mathrm{g}^{-1}, 3986.94 \mu \mathrm{g} \cdot \mathrm{g}^{-1}$ and $350.55 \mu \mathrm{g} \cdot \mathrm{g}^{-1}$ in YAL, QL, HL and ML, respectively. The highest total flavonoid content was found in YAL and the flavonoid in YAL, which was 29.2 folds of that in ML, 67.4 folds of that in P and 129.8 folds of that in F. On the other hand, it was interesting to find that the concentration of some flavonoids from different tissues, such as isorhamnetin-3-O-glucoside, kaempferol-3-O-Rutinoside and quercetin-3-O-glucoside, showed significant differences in 
different maturity. Quercetin compounds were the most widely distributed in A. arguta (Table 3). However, the levels of isorhamnetin and kaempferol compounds were higher than those of quercetins in HL. The content of isorhamnetin compounds in YAL was the highest followed by quercetin and kaempferol compounds. Among the flavonoids in QL, kaempferol compounds were present at the highest level, followed by isorhamnetin and quercetin compounds (relatively low). The content of isorhamnetin compounds was the highest in HL, followed by kaempferol and quercetin compounds. The content of isorhamnetin compounds was highest in ML, followed by quercetin and kaempferol compounds. However, the levels of quercetin compounds were the highest in $\mathrm{P}$ and $\mathrm{F}$, followed by isorhamnetin and kaempferol compounds.

Table 2. Chromatographic and spectraldata of flavonoid glycosides from Actinidia arguta leaves

\begin{tabular}{|c|c|c|c|c|c|}
\hline Constituent & $\begin{array}{l}\text { Retention } \\
\text { time/min }\end{array}$ & $\begin{array}{l}\lambda \max \text { in the } \\
\text { visible region } \\
(\mathrm{nm})\end{array}$ & $\begin{array}{l}\text { Molecular ion / } \\
{[\mathrm{M}+\mathrm{H}]^{+}}\end{array}$ & $\begin{array}{l}\text { Fragment } \\
\text { ions/ (m/z) }\end{array}$ & M.W.(Da) \\
\hline $\mathrm{F} 1$ & 12.188 & 266,350 & 595 & 287 & 594 \\
\hline $\mathrm{F} 2$ & 13.276 & 266,350 & 595 & 287 & 594 \\
\hline F3 & 13.693 & 267,354 & 595 & 287 & 594 \\
\hline $\mathrm{F} 4$ & 10.772 & 256,356 & 757 & 317 & 756 \\
\hline F5 & 11.339 & 257,358 & 757 & 317 & 756 \\
\hline F6 & 14.363 & 266,350 & 625 & 317 & 624 \\
\hline F7 & 14.602 & 254,358 & 625 & 317 & 624 \\
\hline F8 & 14.915 & 263,356 & 625 & 317 & 624 \\
\hline F9 & 14.609 & 259,357 & 653 & 317 & 652 \\
\hline F10 & 21.799 & 260,359 & 579 & 301 & 578 \\
\hline
\end{tabular}


Table 3. The contents of flavonoids in different parts of leaves in CJ-1.

\begin{tabular}{|c|c|c|c|c|c|c|}
\hline Type & YAL $\left(\mu g \cdot g^{-1}\right)$ & $Q L\left(\mu g \cdot g^{-1}\right)$ & HL $\left(\mu g \cdot g^{-1}\right)$ & $\operatorname{ML}\left(\mu g \cdot g^{-1}\right)$ & $P\left(\mu g \cdot g^{-1}\right)$ & $F\left(\mu g \cdot g^{-1}\right)$ \\
\hline Kaempferol-3-O-Rutinoside (+) & $121.19 \pm 8.53 \mathrm{f}$ & - & $397.11 \pm 24.59 c$ & $7.36 \pm 0.52 \mathrm{~d}$ & - & - \\
\hline Kaempferol-3-O-Rutinoside (-) & $775.95 \pm 45.80 \mathrm{c}$ & $456.45 \pm 28.86 \mathrm{~cd}$ & - & $14.33 \pm 1.07 \mathrm{~cd}$ & $0.56 \pm 0.03 \mathrm{e}$ & - \\
\hline Kaempferol-3-O- Neohesperidoside $\quad(\mathrm{P})$ & $1999.91 \pm 125.80 \mathrm{~b}$ & $1326.07 \pm 82.84 b$ & $990.58 \pm 59.92 \mathrm{a}$ & $24.05 \pm 2.19 \mathrm{c}$ & $10.68 \pm 0.62 \mathrm{~cd}$ & $3.23 \pm 0.19 \mathrm{c}$ \\
\hline $\begin{array}{l}\text { isorhamnetin-3-O- } \alpha \text {-L-rhamnopyranosyl - }(1 \rightarrow 3) \text { - } \alpha \text { - L - rhamnopyranosyl } \\
\text { - }(1 \rightarrow 6) \text { - } \beta \text { - D - galactopyranoside }\end{array}$ & $572.36 \pm 34.78 \mathrm{~cd}$ & $499.85 \pm 29.61 \mathrm{c}$ & $1101.83 \pm 70.97 \mathrm{a}$ & $56.44 \pm 4.58 \mathrm{~b}$ & $13.53 \pm 0.81 \mathrm{c}$ & $5.65 \pm 0.33 \mathrm{c}$ \\
\hline $\begin{array}{l}\text { isorhamnetin-3-O- } \alpha \text {-L-rhamnopyranosyl - }(1 \rightarrow 3)-\alpha-L \text { - rhamnopyranosyl } \\
\text { - }(1 \rightarrow 6) \text { - } \beta \text { - D - galactopyranoside }\end{array}$ & $401.43 \pm 24.92$ def & $323.55 \pm 20.53$ de & $697.98 \pm 43.18 \mathrm{~b}$ & $57.35 \pm 4.03 \mathrm{~b}$ & $1.32 \pm 0.01 \mathrm{e}$ & $0.95 \pm 0.05 \mathrm{c}$ \\
\hline isorhamnetin-3-O-neohesperidoside $(\mathrm{P})(+)$ & $212.87 \pm 13.58$ ef & - & $28.36 \pm 1.89 \mathrm{~d}$ & $8.59 \pm 0.59 \mathrm{~d}$ & - & - \\
\hline isorhamnetin-3-O-neohesperidoside $(\mathrm{P})(-)$ & $2103.58 \pm 133.21 b$ & $592.69 \pm 36.25 c$ & $115.43 \pm 9.24 \mathrm{~d}$ & $53.39 \pm 3.59 \mathrm{~b}$ & $30.46 \pm 1.75 b$ & $12.36 \pm 0.74 \mathrm{~b}$ \\
\hline isorhamnetin-3-O-rutinoside & $446.09 \pm 31.49$ de & $210.33 \pm 13.04$ ef & $62.35 \pm 4.23 \mathrm{~d}$ & $11.27 \pm 0.93 \mathrm{~d}$ & $5.69 \pm 0.32 \mathrm{de}$ & - \\
\hline isorhamnetin-3-O-neohespeidoside & $252.63 \pm 16.26$ ef & $89.95 \pm 5.65 \mathrm{f}$ & - & $7.05 \pm 0.45 \mathrm{~d}$ & - & - \\
\hline Quercetin -3-O- rhamnoglycoside & $3333.83 \pm 221.73$ a & $1478.94 \pm 86.92 \mathrm{a}$ & $593.31 \pm 44.91 \mathrm{~b}$ & $110.72 \pm 7.69 \mathrm{a}$ & $89.38 \pm 5.16$ a & $56.55 \pm 3.32 \mathrm{a}$ \\
\hline TF contents $\left(\mu \mathrm{g} \cdot \mathrm{g}^{-1}\right)$ & $10219.84 \pm 1136.36$ & $4977.83 \pm 526.03$ & $3986.94 \pm 448.49$ & $350.55 \pm 44.39$ & $151.63 \pm 15.07$ & $78.75 \pm 8.04$ \\
\hline
\end{tabular}

Note: YAL, Young apical leaves; QL, Leaves expanded to 1/4 to 1/3 of the full leaf size; HL, Leaves expanded to 1/2 to 2/3 of the full leaf size; ML, Mature leaves; P, Petioles of young apical leaves; F, Fruits; - means failure to be detected. 


\section{Discussion}

\subsection{Nutrient content and changing law of different parts of Actinidia arguta}

In previous report, the maturity was important to the nutritional quality of fruits and vegetables [28]. The content of bioactive compounds and antioxidant capacity in leaves were impacted by the maturation degree, such as Vc [29], total carotenoids, total polyphenol [30], etc. Lisiewska et al. noted diminishing Vc concentrations with dill growth [31]. In our study, the Vc content decreased as the leaf became mature, and $\mathrm{Vc}$ concentrations of fruits were lower than those of immature leaves and petioles, while higher than mature leaves. However, Yamada et al. [32] and Omary et al. [33] found an opposite tendency in leaf maturity development of broccoli and spinach, respectively.

In some plants, the polyphenols concentrations also decrease with the leaf maturity, such as in aronia [34]. The polyphenols in levels of Cosmos caudatus were decreased with maturity [35], and the highest phenolic compounds were observed at the young leaves stages of Rosmarinus officinalis [36]. In blackberry, raspberry, and strawberry leaves, Wang and Lin [37] also found the same tendency. At present, there were few reports on the evaluation of A. arguta leaves. According to Thi and Hwang [34] total polyphenol content of aronia leaves was lower than that of the aronia fruit, while the TFC of leaves was approximately twice that of fruits. In our study, the TFC and TPC decreased with the increase of maturity, while in A. arguta fruits, the TPC was higher than that of leaves and petioles, but TFC was lower than leaves and petioles. The FAA content in different parts of the leaves and different tissues showed a trend of declining with the maturity. The FAA content in the petiole of young leaves was not much different from that in young leaves, but they were higher than that of in fruits. This was consistent with the result of Song et al., [38] which reported that the total FAA showed decreasing tendency with the maturity.

\subsection{The leaf flavonoids identification of Actinidia arguta}

The LC-MS/MS was a useful technique to conduct structural identification of flavonol aglycone type [39,40,27]. The LC-MS/MS method had been developed for the rapid screening and determination of bioactive compounds in fruit efficiently and sensitively [41]. Singh et al. [40] identified quercetin-O-pentohexoside, quercetin-3-diglucoside, quercetin-O-xylo-pentoside and kaempferol-O-glucoside using LC-MS/MS and found some molecular ions in the full scan mass spectra, such as m/z 625, m/z 595, m/z 579, and some other ion fragments, including m/z 301, m/z 285. The LC-MS/MS analysis was used to determine the overall composition of the leaf flavonoids in A. arguta in this study and in the light of the UV-vis spectrum, ten peaks had characteristic absorption peak at $240-280 \mathrm{~nm}$ and $330-380 \mathrm{~nm}$, which indicated that these compounds were all flavonol glycoside compound [42,43]. It was found that the concentration of some flavonoids from different tissues showed significant differences in different maturity.

\subsection{The potentialities of $A$. arguta leaves}

In recent years, the antioxidant phytochemicals, have been reported to restrain free radical reactions propagating, such as flavonoids and other polyphenols to defend the human body against diseases and increase life expectancy [44,45]. Simultaneously, considerable regard has been devoted to the development of natural antioxidants of plants origin, including Salvia [46], and Prunus salicina [47]. Our study indicated that the flavonoid components in young leaves of A. arguta contained quercetin, kaempferol and isorhamnetin compounds, and the content of total flavonoid was higher than that of mature leaves. Maybe the young leaves would be processed into tea in the future, like Ginkgo biloba [48], pear jujube [49], and Lycium barbarum [50]. Therefore, if the leaves can also be processed and utilized, A. arguta would usher in greater business opportunities in addition to producing fresh fruit. 


\section{Materials and Methods}

\subsection{Plant Materials}

Eight $A$. arguta accessions were collected from Northeast of China, which were A. arguta cv. Changjiang No.1 ('CJ-1', female plant), A. arguta cv. Huanyou No.1 ('HY-1', female plant), BYS No. 13 ('BYS-13', male plant), CBS No. 3 ('CBS-3', female plant), CBS No. 6 ('CBS-6', female plant), CBS No. 11 ('CBS-11', male plant), CBS No. 8 ('CBS-8', female plant) and BYS No. 5 ('BYS-5', female plant) (Table 4, Figure S3). They were grown in the open field in the Germplasm Resource Repository of Wild Kiwifruit in Shenyang Agricultural University, with the space of $2 \times 5 \mathrm{~m}$ arranged with drip irrigation. The fresh leaves of the eight accessions were collected at summer pruning stage in the middle of June, and mature fruits were collected from the middle of August to the middle of September, 2018. Six tissues were collected for analysis, including young apical leaves (YAL), leaves expanded to $1 / 4$ to $1 / 3$ of the full leaf size (QL), leaves expanded to $1 / 2$ to $2 / 3$ of the full leaf size $(\mathrm{HL})$, mature leaves $(\mathrm{ML})$, petioles of young apical leaves $(\mathrm{P})$ and fruits $(\mathrm{F})$ (Figure 8). The samples were collected and wrapped in tinfoil, temporary frozen with liquid nitrogen and kept in $-80{ }^{\circ} \mathrm{C}$ refrigerator. Triplicate samples were made with each 10 plants, and $10 \mathrm{~g}$ leaves and $100 \mathrm{~g}$ mature fruits in total were sampled randomly and pooled to constitute the replicates.

Table 4. The geographical description of the eight Actinidia arguta accessions examined in this study

\begin{tabular}{lllll}
\hline Accessions & Accessions sources & Latitude and longitude & Altitude $(\mathrm{m})$ & Plant sex \\
\hline CJ-1 & Shenyang,Liaoning & $123^{\circ} 43^{\prime} \mathrm{E}, 41^{\circ} 80^{\prime} \mathrm{N}$ & 55 & female \\
HY-1 & Benxi,Liaoning & $125^{\circ} 35^{\prime} \mathrm{E}, 41^{\circ} 27^{\prime} \mathrm{N}$ & 282 & female \\
BYS-13 & Zhuanghe,Liaoning & $122^{\circ} 98^{\prime} \mathrm{E}, 39^{\circ} 70^{\prime} \mathrm{N}$ & 1078 & male \\
CBS-3 & Changbaishan,Jilin & $100^{\circ} 12^{\prime} \mathrm{E}, 40^{\circ} 15^{\prime} \mathrm{N}$ & 2579 & female \\
CBS-6 & Changbaishan,Jilin & $100^{\circ} 13^{\prime} \mathrm{E}, 40^{\circ} 18^{\prime} \mathrm{N}$ & 2623 & female \\
CBS-11 & Changbaishan,Jilin & $100^{\circ} 11^{\prime} \mathrm{E}, 40^{\circ} 15^{\prime} \mathrm{N}$ & 2637 & male \\
CBS-8 & Changbaishan,Jilin & $100^{\circ} 13^{\prime} \mathrm{E}, 40^{\circ} 17^{\prime} \mathrm{N}$ & 2583 & female \\
BYS-5 & Zhuanghe,Liaoning & $122^{\circ} 97^{\prime} \mathrm{E}, 39^{\circ} 73^{\prime} \mathrm{N}$ & 1074 & female \\
\hline
\end{tabular}

4.2 Determination of bioactive compounds in leaves and fruits of A. arguta

\subsubsection{Vitamin C (Vc) content}

The Vc contents in leaves and fruits were determined according to the method of Yoon et al. with some improvement [51]. Freeze-dried sample $(0.2 \mathrm{~g})$ was ground into homogenate with $5 \mathrm{~mL}$ of oxalic acid-Ethylene Diamine Tetraacetic Acid (EDTA), then the distilled water was used to make total volume to $10 \mathrm{~mL}$. The extract $(5 \mathrm{~mL})$ was mixed with $0.5 \mathrm{~mL}$ of metaphosphoric acid-acetic acid solution, $1 \mathrm{~mL}$ of 1:19 sulfuric acid, and $2 \mathrm{~mL}$ of $5 \%$ ammonium molybdate solution. After $15 \mathrm{~min}$, the mixture was centrifuged for $15 \mathrm{~min}$ at $4000 \mathrm{r} / \mathrm{min}$. The absorbance at $760 \mathrm{~nm}$ was recorded using spectrophotometer. The total content was calculated using $\mathrm{Vc}_{\mathrm{c}}$ as standard. 

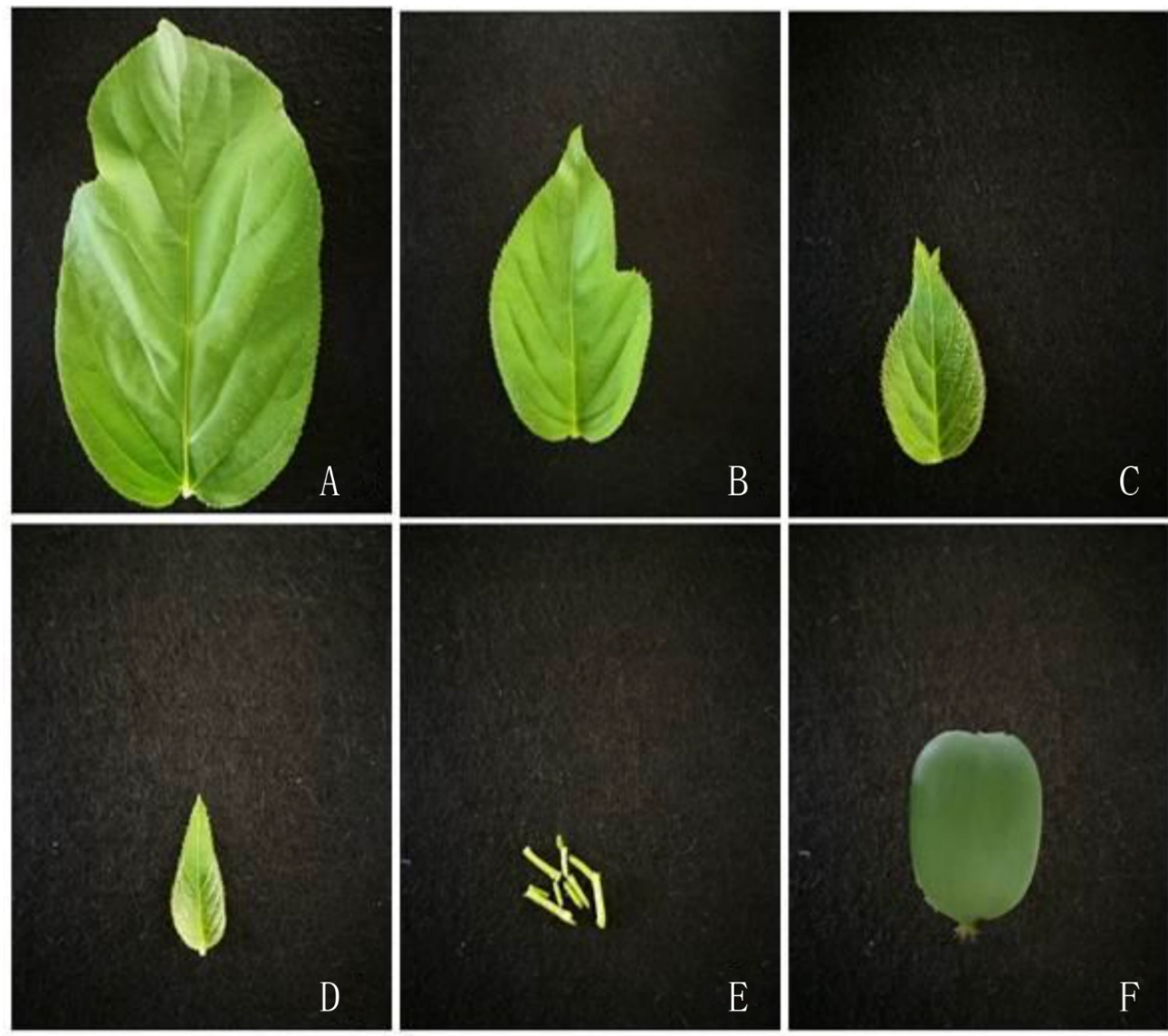

Figure 8. Four types of leaves, petioles and fruits of $A$. arguta accessions. (A) Mature leaves (ML); (B) Leaves expanded to $1 / 2$ to $2 / 3$ of the full leaf size (HL); (C) Leaves expanded to $1 / 4$ to $1 / 3$ of the full leaf size (QL); (D) Young apical leaves (YAL); (E) Petioles of young apical leaves (P); (F) Fruits (F).

\subsubsection{Soluble sugar content (SSC)}

SSC of the leaves and fruits were determined according to the method of Liu et al. with some modifications [52]. Freeze-dried sample $(0.2 \mathrm{~g})$ was finely powdered and added $15 \mathrm{~mL}$ of distilled water and placed in boiling water bath 15 minutes. After that final volume was made to $25 \mathrm{~mL}$ with distilled water. The extract $(1 \mathrm{~mL})$ was mixed with $5 \mathrm{~mL}$ of anthrone reagent. After $10 \mathrm{~min}$ of boiling in water bath, the absorbance at $620 \mathrm{~nm}$ was recorded using spectrophotometer. The glucose was used as standard. The result was represented as $\mathrm{mg} / \mathrm{g}$ fresh weight $(\mathrm{mg} / \mathrm{g}$. FW).

\subsubsection{Free amino acid (FAA) content}

The FAA contents of the leaves and fruits were determined with some modification of the method proposed by Avino et al. [53]. Freeze-dried sample ( $0.1 \mathrm{~g})$ was ground into homogenate with acetic acid $(10 \%)$, and the ammonia-free distilled water was used to make total volume to $10 \mathrm{~mL}$. The extract $(2 \mathrm{~mL})$ was mixed with $3 \mathrm{~mL}$ of ninhydrin reagent and $0.1 \mathrm{~mL}$ of ascorbic acid solution and placed in boiling water bath for $15 \mathrm{~min}$. The absorbance was recorded at $570 \mathrm{~nm}$ using spectrophotometer. The leucine was used as standard.

\subsubsection{Total phenolic content (TPC)}

The TPC in A. arguta extracts was determined according to Folin Ciocalteu method of Navajas-Porras et al. with slight improvement [54]. Freeze-dried sample (0.2 g) was chopped and added $10 \mathrm{~mL}$ of distilled water and placed in boiling water bath for $10 \mathrm{~min}$. After that, the solution was centrifuged for $10 \mathrm{~min}$ at $3000 \mathrm{r} / \mathrm{min}$. The extract of A. arguta $(250 \mu \mathrm{L})$ was added to $1 \mathrm{~mL}$ distilled water, followed by Folin-Ciocalteu reagent $(250 \mu \mathrm{L})$ and then $7 \%$ sodium carbonate $(2.5 \mathrm{~mL})$ was 
105

106

107

108

109

110

111

112

113

114

115

116

added to the mixture. The distilled water was used to make total volume to $10 \mathrm{~mL}$ and placed at room temperature for $1.5 \mathrm{~h}$. The absorbance at $760 \mathrm{~nm}$ was recorded using spectrophotometer. The gallic acid was used as standard.

\subsubsection{Total flavonoids content (TFC)}

The TFC was determined by the method of Zainudin et al. with minor modifications [30]. The sample $(0.5 \mathrm{~g})$ was finely powdered and extracted with $10 \mathrm{~mL}$ formic-methanol $(0.2 \%)$, centrifuged at $5000 \mathrm{r} / \mathrm{min}$ for $10 \mathrm{~min}$. The extract $(5 \mathrm{~mL})$ was added to $0.3 \mathrm{~mL}$ of sodium nitrite $\left(\mathrm{NaNO}_{2}, 5 \% \mathrm{w} / \mathrm{v}\right)$, and then $0.3 \mathrm{~mL}$ of aluminium chloride $\left(\mathrm{AlCl}_{3}, 10 \% \mathrm{w} / \mathrm{v}\right)$ and $4 \%$ sodium hydroxide solution $(2 \mathrm{~mL})$ were added every $6 \mathrm{~min}$, respectively. The distilled water was used to make total volume to $10 \mathrm{~mL}$, which kept for $10 \mathrm{~min}$. The absorbance at $510 \mathrm{~nm}$ was recorded using spectrophotometer. The rutin was used as standard. The result was represented as $\mathrm{mg} / \mathrm{g}$ fresh weight (mg/g. FW).

\subsection{Antioxidant activity assay}

\subsubsection{ABTS radical scavenging activity}

The ABTS radical scavenging activity was performed with minor modifications according to the spectrophotometric method of Chandel et al. [55]. The reaction mixture containing ratio of 1: 2 including $2.45 \mathrm{mmol} / \mathrm{L}$ potassium persulfate solution and $7 \mathrm{mmol} / \mathrm{L}$ aqueous solution of $\mathrm{ABTS}$ (ABTS+·). The mixture was kept in dark for $14 \mathrm{~h}$ at $29^{\circ} \mathrm{C}$, and then it was diluted with ethanol in order to obtain an absorbance at $734 \mathrm{~nm}$ of $0.7 \pm 0.02$ units. The extracts or reference substances (Trol ox) (200 $\mu \mathrm{L}$ ) were added to $3 \mathrm{~mL}$ of ABTS radical solution in a dark condition and the absorbance was measured at $734 \mathrm{~nm}$ after six min.

ABTS radical-scavenging activity $(\%)=\left(\left(\mathrm{A}_{0}-\mathrm{A}_{1}\right) / \mathrm{A}_{0}\right) \times 100 \%$

where $A_{0}$ is the absorbance of ABTS radical absolute ethanol solution, and $A_{1}$ is the absorbance of the mixture ABTS radical extract.

\subsubsection{DPPH radical scavenging activity}

The DPPH method was used to determine the free radical scavenging activity of the extract [56]. In order to obtain the antioxidant activity, $0.2 \mathrm{~g}$ sample was extracted with $10 \mathrm{~mL}$ of absolute ethanol and filtered. Then $2 \mathrm{~mL}$ solution was taken and mixed with $2 \mathrm{~mL}$ of $0.2 \mathrm{mmol} / \mathrm{L}$ DPPH absolute ethanol solution. The mixture was kept at room temperature and protected from light for $30 \mathrm{~min}$, and the absorbance was recorded at $517 \mathrm{~nm}$.

DPPH radical scavenging activity $(\%)=\left(\left(\mathrm{A}_{0}-\mathrm{A}_{1}\right) / \mathrm{A}_{0}\right) \times 100 \%$

Where $A_{0}$ is the absorbance of DPPH ethanol solution, and $A_{1}$ is the absorbance of the mixture of $\mathrm{DPPH}$ and extract.

\subsection{Analysis of Flavonoids Compounds Using LC-MS/MS}

The flavonoid compounds were determined using LC-MS/MS analysis (Figure 9). The content of ten flavonoid compounds in different tissues of 'CJ-1' was quantitatively analyzed. Chromatographic analysis was conducted on an Agilent 6410 Triple Quad LC-MS/MS (Agilent Technologies, USA) with 1260 liquid chromatography system and electrospray ionization source (electronic spray ionization, ESI). The chromatographic separation column was Agilent Poroshell 120 SB-C18 column $(2.1 \times 100$ $\mathrm{mm}, 2.7 \mu \mathrm{m}$, Agilent Technologies, USA). A volume of $10 \mu \mathrm{L}$ sample solution was injected for LC-MS/MS analysis with flow rate of $0.3 \mathrm{~mL} / \mathrm{min}$. Flavones and flavonols were detected at $350 \mathrm{~nm}$. The mobile phases A and B were composed of $2.5 \%(\mathrm{v} / \mathrm{v})$ formic acid in water and $2.5 \%(\mathrm{v} / \mathrm{v})$ formic acid in acetonitrile, respectively. The column was eluted using linear gradients at $30^{\circ} \mathrm{C}: 0 \mathrm{~min}, 100 \% \mathrm{~A}$, $0 \% \mathrm{~B} ; 3 \mathrm{~min}, 90 \% \mathrm{~A}, 10 \% \mathrm{~B} ; 5 \mathrm{~min}, 86.5 \% \mathrm{~A}, 13.5 \% \mathrm{~B} ; 7 \mathrm{~min}, 86.5 \% \mathrm{~A}, 13.5 \% \mathrm{~B} ; 8 \mathrm{~min}, 86 \% \mathrm{~A}, 14 \% \mathrm{~B} ; 9$ $\min , 85 \%$ A, $15 \%$ B; $10 \min , 85 \%$ A, $15 \%$ B; 11 min, $84.5 \%$ A, $15.5 \%$ B; 12 min, $83.5 \%$ A, $16.5 \%$ B; 12.5 $\min , 82 \%$ A, $18 \%$ B; $13 \mathrm{~min}, 70 \%$ A, 30\% B; $13.5 \mathrm{~min}, 69.5 \%$ A, 30.5\% B; $14 \mathrm{~min}, 68.5 \% \mathrm{~A}, 31.5 \% \mathrm{~B} ; 17$ $\min , 60 \%$ A, $40 \%$ B; $20 \mathrm{~min}, 0 \% \mathrm{~A}, 100 \% \mathrm{~B} ; 23 \mathrm{~min}, 95 \% \mathrm{~A}, 5 \% \mathrm{~B} ; 25 \mathrm{~min}, 95 \% \mathrm{~A}$ and $5 \% \mathrm{~B}$. The MS 
151

152

153

154

155

156

157

158

conditions were: electrospray ionization, positive ion mode; gas (N2) temperature $300{ }^{\circ} \mathrm{C}$; nebulizer pressure, 15 psi; capillary voltage, $4000 \mathrm{~V}$; capillary exit, $200 \mathrm{~V}$. Mass spectra from m/z 100 to $1000 \mathrm{~nm}$ were recorded. The analysis of data was conducted using LC/MSD Trap Software 5.3. Naringenin, quercetin 3-O-rutinoside, myricetin, quercetin, dihydroquercetin, kaempferol, dihydromyricetin, dihydrokaempferol, (+)-catechin, (-)-epicatechin obtained from the National Institutes for Food and Drug Control, Beijing, China, and the standard for quantification was quercetin 3-O-rutinoside. The contents of total flavonoids were calculated at $350 \mathrm{~nm}$. Each sample was analyzed in triplicates.

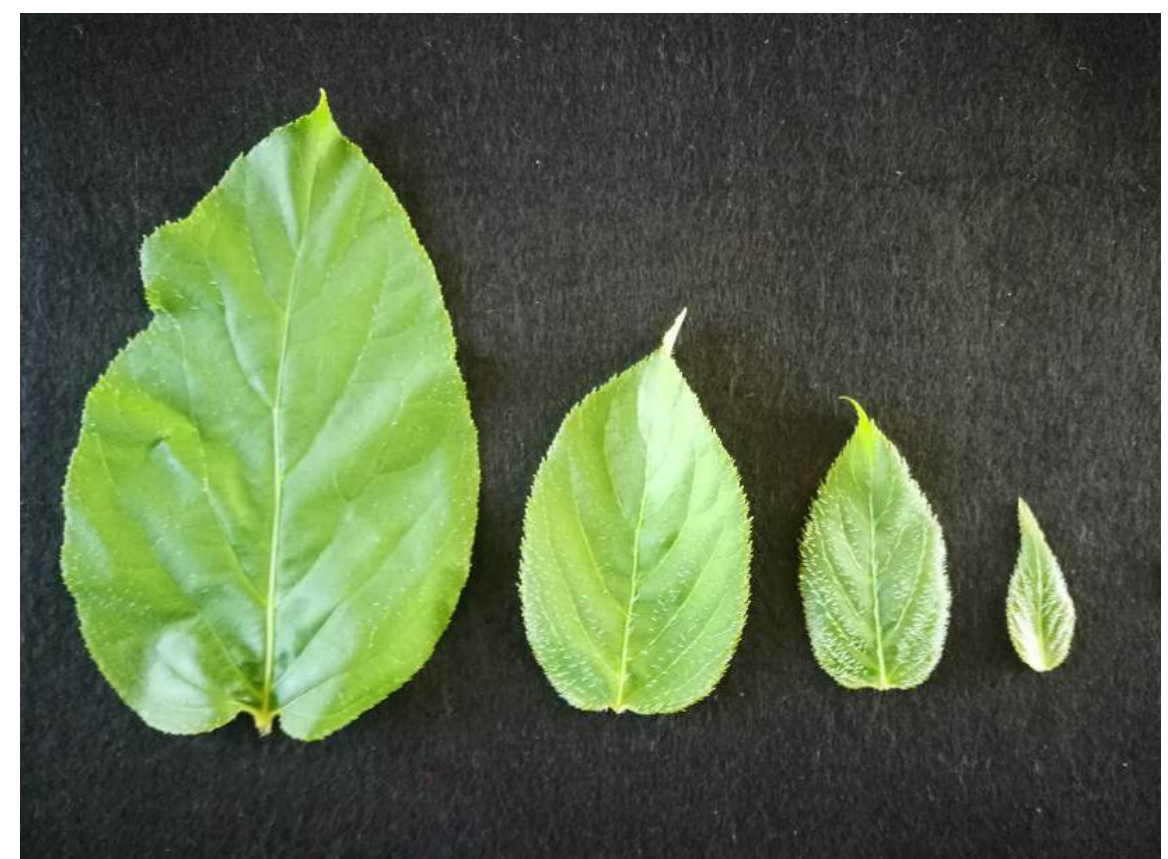

Figure 9. Four types of leaves of eight A. arguta accessions used in LC-MS/MS.

\subsection{Statistical Analysis}

Analyses of variance was performed using SPSS 19.0 statistical analysis software. All experimental data was presented as means from triplicates standard deviations. The data significance was checked at $p \leq 0.05$. A Pearson's correlation analysis was conducted between the antioxidant capacity and bioactive compounds.

\section{Conclusions}

A. arguta is rich in vitamin $\mathrm{C}$ and bioactive and volatile compounds with high antioxidant activities, such as flavonoids, phenolic compounds, etc. This study evaluated the eight wild A. arguta accessions and different tissues according to the bioactive compounds and antioxidant activities. The contents of different bioactive compounds in the eight accessions varied greatly, and 'CJ-1' and 'CBS-8' had relatively outstanding performance. According to the comprehensive evaluation of the antioxidant activity among different tissues, the young leaves had the strongest antioxidant activity. These results provided a theoretical basis for further utilization of leaves of A. arguta.

Supplementary Materials: The following are available online at www.mdpi.com/xxx/s1, Figure S1: LC-MS analysis of the crude extract from leaves of Actinidia arguta in positive ion mode. Selected ion chromatograms of $\mathrm{m} / \mathrm{z} 595,757,625,653,579$ respectively, with the retention time of corresponding constitutions, Figure S2: LC-MS2 spectra of $[\mathrm{M}+\mathrm{H}]^{+}$ion for the ten constituents, Figure S3: Fruits (female) or flowers (male) of eight accessions in Actinidia arguta. a; CJ-1; b: HY-1; c: CBS-3; d: CBS-11; e: CBS-6; f: CBS-8; g: BYS-13; h: BYS-5. 
178

179

180

181

182

183

184

185

186

187

188

189

190

191

192

193

194

195

196

197

198

199

200

201

202

203

204

205

206

207

208

209

210

211

212

213

214

215

216

217

218

219

220

221

222

223

224

225

226

227

228

229

230

231

232

233

Author Contributions: conducted the experiment, analyzed the data, and wrote the manuscript, C.T.; writing-review and editing, Z.W., M.I; methodology, X.F.; supervision, C.L. All authors have read and agreed to the published version of the manuscript.

Funding: This research received no external funding.

Conflicts of Interest: The authors declare no conflict of interest.

\section{References}

1. Ferguson, A.R. Kiwifruit (Actinidia). Genetic Resources of Temperate Fruit \& Nut Crops 1990, 290, $603-656$.

2. Vorobiev, D. P. Review of Far East species of genera Actinidia Lindley. Bulletin of Gornotaiegny Station of Far East Branch of the Academy of Sciences of USSR. Chabarovsk 1939, 3, 5-38.

3. Kabaluk, J T.; Kempler, C.; Toivonen, P.M.A. Actinidia arguta - characteristics relevant to commercial production. Fruit Varieties J 1997, 51(2), 117-122.

4. Latocha, P.; Woosiak, R.; Worobiej, E.; Krupa, T. Clonal differences in antioxidant activity and bioactive constituents of hardy kiwifruit (Actinidia arguta) and its year-to-year variability. J Sci Food Agric 2012, 93(6), 1412-1419.

5. Leontowicz, H.; Leontowicz, M.; Latocha, P.; Jesion, I.; Park, Y.S.; Katrich, E.; Barasch, D.; Nemirovski, A.; Gorinstein, S. Bioactivity and nutritional properties of hardy kiwifruit Actinidia arguta in comparison with Actinidia deliciosa 'Hayward' and Actinidia eriantha 'Bidan'. Food Chem 2016, 196, 281-291.

https://doi.org/10.1016/j.foodchem.2015.08.127.

6. Matich, A.J.; Young, H.; Allen, J.M.; Wang, M.Y.; Fielder, S.; McNeilage, M.A.; MacRae, E.A. Actinidia arguta: volatile compounds in fruit and flowers. Phytochemistry 2003, 63(3), 285-301.

https://doi.org/10.1016/S0031-9422(03)00142-0.

7. Liang, C.F. On the distribution of Actinidia. Guihaia 1983, 3, 229-248.

8. Ferguson, R.; Huang, H. Genetic resources of kiwifruit: domestication and breeding. Horticultural Reviews 2007, 33, 1-121. https://doi.org/10.1002/9780470168011.ch1.

9. Latocha, P.; and Krupa, T. Morphological, chemical and sensory analyses of promising genotypes of hardy kiwifruit (Actinidia Lindl.) obtained in the breeding programme at WULS. Ann Warsaw Univ Life Sci -SGGW, Hortic Landsc Architect 2007, 28, 111-119.

10. Xu, X.; Zhang, Q. Researches and Utilizations of Germplasm Resource of kiwifruit in China. Chinese Bull Bot 2003, 020(006), 648-655. (in Chinese)

11. Jung, K.A.; Song, T.C.; Han, D.; Kim, I.H.; Kim, Y.E.; Lee, C.H. Cardiovascular protective properties of kiwifruit extracts in vitro. Biol Pharmac Bull 2005, 28, 1782-1785.

12. Park, Y.S.; Leontowicz, H.; Leonowicz, M.; Namiesnik, J.; Suhaj, M.; Cvikrov'a, M.; Martincova', O.; Gorinstein, M.W.S. Comparison of the contents of bioactive compounds and the level of antioxidant activity in different kiwifruit cultivars. J Food Comp Anal 2011, 24, 963-970.

13. Li, Y.; Fang, J.; Qi, X.; Lin, M.; Zhong, Y.; Sun, L. A key structural gene, AaLDOX, is involved in anthocyanin biosynthesis in all red-fleshed kiwifruit (Actinidia arguta) based on transcriptome analysis. Gene 2018, 648,31-41. https://doi.org/10.1016/j.gene.2018.01.022.

14. Pérez-Burillo, S.; Oliveras, M.J.; Quesada, J.; Rufián-Henares, J.A.; Pastoriza, S. Relationship between composition and bioactivity of persimmon and kiwifruit. Food Res Int 2018, 105, 461-472.

https://doi.org/10.1016/j.foodres.2017.11.022.

15. Wang, L.; Tang, W.; Hu, Y.; Zhang, Y.; Sun, J.; Guo, X.; Lu, H.; Yang, Y.; Fang, C.; Niu, X.; Yue, J.; Fei, Z.; Liu, Y. A MYB/bHLH complex regulates tissue-specific anthocyanin biosynthesis in the inner pericarp of red-centered kiwifruit Actinidia chinensis cv. Hongyang. The Plant J 2019, 99,359-378. https://doi.org/10.1111/tpj.14330.

16. Li, W.; Ding, Z.; Ruan, M.; Yu, X.; Peng, M.; Liu, Y. Kiwifruit R2R3-MYB transcription factors and contribution of the novel AcMYB75 to red kiwifruit anthocyanin biosynthesis. Sci Rep-UK 2017, 7(1), 16861. https://doi.org/10.1038/s41598-017-16905-1.

17. Wang, H.; Cao, G.; Prior, R.L. Total antioxidant capacity of fruits. J Agric Food Chem 1996. 44, 701-705.

18. Latocha, P.; Krupa, T.; Wolosiak, R.; Worobiej, E.; Wilczak, J. Antioxidant activity and chemical difference in fruit of different Actinidia sp. Int J Food Sci Nutr 2010, 61, 381-394.

19. Almeida, D.; Pinto, D.; Santos, J.; Vinha, A.F.; Palmeira, J.; Ferreira, H.N.; Rodrigues, F.; Oliveira, M.B.P. Hardy kiwifruit leaves (Actinidia arguta): An extraordinary source of value-added compounds for food industry. Food chem 2018, 259, 113-121. https://doi.org/10.1016/j.foodchem.2018.03.113.

20. Li, Y.; Fang, J.; Qi, X.; Lin, M.; Zhong, Y.; Sun, L.; Cui, W. Combined analysis of the fruit metabolome and transcriptome reveals candidate genes involved in flavonoid biosynthesis in Actinidia arguta. Int J Mol Sci 2018, 19,1471. http://dx.doi.org/10.3390/ijms19051471. 
21. Wojdylo, A.; Nowicka, P. Anticholinergic effects of Actinidia arguta fruits and their polyphenol content determined by liquid chromatography-photodiode array detector-quadrupole/time off light-mass spectrometry (LC-MS-PDA-Q/TOF). Food Chem 2019, 271, 216-223. https://doi.org/10.1016/j.foodchem.2018.07.084.

22. Yu, M., Man, Y.; Lei, R.; Lu, X.; Wang, Y. Metabolomics study of flavonoids and anthocyanin-related gene analysis in kiwifruit (Actinidia chinensis) and kiwiberry (Actinidia arguta). Plant Mol Biol Rep 2020, 38, 353-369.

23. Zuo, L.L.; Wang, Z.Y.; Fan, Z.L.; Tian, S.Q.; Liu, J.R. Evaluation of antioxidant and antiproliferative properties of three Actinidia (Actinidia kolomikta, Actinidia arguta, Actinidia chinensis) extracts in vitro. Int J Mol Sci 2012, 13, 5506-5518. doi:10.3390/ijms13055506.

24. Zhao, G.; Dai S.; Chen R. Dictionary of Traditional Chinese Medicine. Shanghai Science and Technology Press, China, 2006. (in chinese)

25. Cyboran, S.; Oszmiański, J.; Kleszczyńska, H. Modification of the properties of biological membrane and its protection against oxidation by Actinidia arguta leaf extract. Chem-Biol Interact 2014, 222, 50-59. doi:10.1016/j.cbi.2014.08.012

26. Webby, R.F. A flavonol triglycoside from Actinidia arguta var. giraldii. Phytochemistry 1990, 30(7), 2443-2444.

27. Xue, L.; Wang, Z.; Zhang, W.; Li, Y.; Wang, J.; Lei, J. Flower pigment inheritance and anthocyanin characterization of hybrids from pink-flowered and white-flowered strawberry. Sci Hortic-Amsterdam 2016, 200,143-150.

28. Lee, S.K.; Kader, A.A. Preharvest and postharvest factors influencing vitamin C content of horticultural crops. Postharvest Biol Tec 2000,20, 207-220.

29. Wawire, M.; Oey, I.; Mathooko, F.; Njoroge, C.; Shitanda, D.; Hendrickx, M. Thermal stability of ascorbic acid and ascorbic acid oxidase in African cowpea leaves (Vigna unguiculata) of different maturities. J Agr Food Chem 2011, 59(5), 1774-1783.

30. Zainudina, M.A.M.; Hamida, A. A.; Anwarb, F.; Osmana, A.; Saari, N. Variation of bioactive compounds and antioxidant activity of carambola (Averrhoa carambola L.) fruit at different ripening stages. Sci Hortic-Amsterdam 2014, 172, 325-331.

31. Lisiewska, Z.; Kmiecik, W.; Korus, A. Content of vitamin C, carotenoids, chlorophylls and polyphenols in green parts of dill (Anethum graveolens L.) depending on plant height. J Food Compos Anal 2006, 19, 134-140.

32. Yamada, C.; Iwasaki, Y.; Yoshida, K. Effect of growth stage on contents of reducing sugar, ascorbic acid, oxalate and nitrate in spinach. J Jap Soc Nutr Food Sci 2003, 56, 167-173.

33. Omary, M.B.; Brovelli, E.A.; Pusateri, D.J.; David, P.; Rushing, J.W.; Fonseca, J.M. Sulforaphane potential and vitamin $C$ concentration in developing heads and leaves of broccoli (Brassica oleracea var. italica). $J$ Food Quality 2003, 26, 523-530.

34. Thi, N. D.; Hwang, E. S. Bioactive compound contents and antioxidant activity in aronia (Aronia melanocarpa) leaves collected at different growth stages. Preventive Nutr Food Sci 2014, 19(3), 204-212.

35. Dian-Nashiela, F.; Noriham, A.; Nooraain, H.; Azizah, A. H. Antioxidant activity of herbal tea prepared from Cosmos caudatus leaves at different maturity stages. International Food Research Journal 2015, 22(3), 1189-1194.

36. Bãno, M.J-del.; Lorente, J.; Castillo, J.; Benavente-Garcia, O.; Rio, J.A-del.; Ortuno, A.; Quirin, K.W.; Gerard, D. Phenolic diterpenes, flavones, and rosmarinic acid distribution during the development of leaves, flowers, stems, and roots of Rosmarinus officinalis. Antioxidant activity. J Agr Food Chem 2003, 51, 4247-4253.

37. Wang, S.Y.; Lin, H.S. Antioxidant activity in fruits and leaves of blackberry, raspberry, and strawberry varies with cultivar and developmental stage. J Agr Food Chem 2000, 48, 140.

38. Song, J.; Bi, J.; Chen, Q.; Wu, X.; Lyu, Y.; Meng, X. Assessment of sugar content, fatty acids, free amino acids, and volatile profiles in jujube fruits at different ripening stages. Food Chem 2018, 270(1), 344-352.

39. Dartora,N.; de Souza,L.M.; Santana-Filho, A.P.; Iacomini, M.; Valduga, A.T.; Gorin, P. A.J.; Sassaki, G.L. UPLC-PDA-MS evaluation of bioactive compounds from leaves of Ilex paraguariensis with different growth conditions, treatments and ageing. Food Chem 2011, 129, 1453-1461.

40. Singh, A.P.; Wilson, T.; Luthria, D.; Freeman, M.R.; Scott, R. M.; Bilenker, D.; Shah, S.; Somasundaram, S.; Vorsa, N. LC-MS-MS characterisation of curry leaf flavonols and antioxidant activity. Food Chem 2011, 127(1), 80-85.

41. Pandey, R.; Mahar, R.; Hasanain, M.; Shukla, S.K.; Sarkar, J.; Rameshkumar, K.B.; Kumar, B. Rapid screening and quantitative determination of bioactive compounds from fruit extracts of Myristica species and their in vitro antiproliferative activity. Food Chem 2016, 211, 483-493. 
42. Neugart, S.; Zietz, M.; Schreiner, M.; Rohn, S.; Kroh, L. W.; Krumbein, A. Structurally different flavonol glycosides and hydroxycinnamic acid derivatives respond differently to moderate UV-B radiation exposure. Physiol Plantarum 2012, 145(4), 582-593. doi:10.1111/j.1399-3054.2012.01567.x.

43. Du, Q.H.; Zhang, Q.Y.; Han, T.; Jiang, Y.P.; Peng, C.; Xin, H.L. Dynamic changes of flavonoids in Actinidia valvata leaves at different growing stages measured by HPLC-MS/MS. Chin J Nat Med 2016, 14(1), 66-72.

44. Khoobi, M.; Emami, S.; Dehghan, G.; Foroumadi, A.; Ramazani, A.; Shafiee, A. Synthesis and free radical scavenging activity of coumarin derivatives containing a 2-methylbenzothiazoline motif. Archiv Der Pharmazie 2011, 344, 588-594.

45. Arulmozhi, S.; Mazumder, P.M.; Sathiyanarayanan, L.; Ashok, P. Anti-arthritic and antioxidant activity of leaves of Alstonia scholaris Linn. R.Br. Eur J Integr Med 2011, 3(2), e83-e90. https://doi.org/10.1016/j.eujim.2011.04.019.

46. Zupkó, I.; Hohmann, J.; Rédei, D.; Falkay, G.; Janicsák, G.; Máthé, I. Antioxidant activity of leaves of Salvia species in enzyme-dependent and enzyme-independent systems of lipid peroxidation and their phenolic constituents. Planta Med 2001, 67(4), 366-368. https://doi.org/10.1055/s-2001-14327.

47. Delgado-Adámez, J.; Fernández-León, M.F.; Velardo-Micharet, B.; González-Gómez, D.; In vitro assays of the antibacterial and antioxidant activity of aqueous leaf extracts from different Prunus salicina Lindl. cultivars. Food Chem Toxicol 2012, 50(7), 2481-2486. https://doi.org/10.1016/j.fct.2012.02.024.

48. Yuan, D.; Chen, X.; Hou, L.; Jiang, Q.; Liu, F.; Zhu, X. Study on production of Ginkgo biloba tea with pile-fermentation. J Food Sci Biotech 2016, 36(7), 84-89. (in Chinese)

49. Xu, B.; Wang, M.; Cao, J.; Wang, Y. Differences in antioxidant components and activity of pear jujube (Zizyphus jujube Mill. cv. Lizao) leaf tea among different growth stages. Food Sci 2013, 34(13), 34-38. (in Chinese)

50. Zhou, Z.; Cao, Y.; Wang, Y.; Cheng, D.; Mi, J.; Li, X.; Yan, Y.; Zeng, X. Analysis of chemical compositions and antioxidant activities of Lycium barbarum bud and leaf teas. Sci Tech Food Ind 2017, 38(10), 129-145. (in Chinese)

51. Yoon, Y.E.; Kuppusamy, S.; Cho, K. M.; Kim, P.J.; Kwack, Y.B.; Lee, Y. B. Influence of cold stress on contents of soluble sugars, vitamin $\mathrm{c}$ and free amino acids including gamma-aminobutyric acid (GABA) in spinach (spinacia oleracea). Food Chem 2017, 215, 185-192. doi:10.1016/j.foodchem.2016.07.167

52. Liu, H.; Fu, Y.; Hu, D.; Yu, J.; Liu, H. Effect of green, yellow and purple radiation on biomass, photosynthesis, morphology and soluble sugar content of leafy lettuce via spectral wavebands "knock out". Sci Hortic-Amsterdam 2018, 236, 10-17.

53. Avino, P.; Campanella, L.; Russo, M. V. Use of different anticoagulants for HPLC separation and quantification of the free amino acid content of plasma. J Sep Sci 2015, 26(5), 392-396.

54. Navajas-Porras, B.; Pérez-Burillo, S.; Morales-Pérez, J.; Rufián-Henares, J.A.; Pastoriza, S. Relationship of quality parameters, antioxidant capacity and total phenolic content of EVOO with ripening state and olive variety. Food Chem 2020, 325, 126926.

55. Chandel, M.; Sharma, U.; Kumar, N.; Singh, B.; Kaur, S. Antioxidant activity and identification of bioactive compounds from leaves of Anthocephalus cadamba by ultra-performance liquid chromatography/electrospray ionization quadrupole time of flight mass spectrometry. Asian Pac J Trop Med 2012, 5(12), 977-985.

56. Chávez-Mendoza, C.; Sanchez, E.; Muñoz-Marquez, E.; Sida-Arreola, J.P.; Flores-Cordova, M.A. Bioactive compounds and antioxidant activity in different grafted varieties of bell pepper. Antioxidants 2015, 4, 427-446. 